\title{
Rare Presentation of Giant Cell Tumor in the Internal Auditory Canal: Case Report and Review of the Literature
}

\author{
Ajit S. Jada ${ }^{1}$ \\ Raj K. Shrivastava ${ }^{2}$ \\ Abul Mannan ${ }^{3}$ \\ ${ }^{1}$ Department of Neurosurgery, Montefiore Medical Center, Bronx, \\ New York, United States \\ 2 Department of Neurosurgery, The Mount Sinai Medical Center, New \\ York, New York, United States \\ ${ }^{3}$ Department of Pathology, The Mount Sinai Medical Center Roosevelt \\ Division, New York, New York, United States \\ ${ }^{4}$ Department of Otolaryngology, The Mount Sinai Medical Center \\ Roosevelt Division, New York, New York, United States
}

Andrew Kobets ${ }^{1}$

Spiros Manolidis 4

Address for correspondence Ajit S. Jada, MD, 3316 Rochambeau Avenue, Bronx, NY 10467, United States (e-mail: Ajitjada@gmail.com).

J Neurol Surg Rep 2015;76:e65-e71.

\begin{abstract}
Giant cell tumor (GCT) is a benign but locally aggressive bone tumor that usually involves the end of long bones. It is a relatively common neoplasm in patients, constituting 5 to $10 \%$ of all benign bone tumors. Approximately $2 \%$ of GCTs occur in

Keywords

- giant cell tumor

- internal auditory canal

- skull base tumor the craniofacial skeleton with a predilection for the ethmoid, sphenoid, and temporal bones. The skull base location is unique and not commonly described. Hearing loss, headache, tinnitus, and subcutaneous masses are the most commonly reported symptoms in GCTs of the skull base. In this case report we present the first description of a GCT within the internal auditory canal causing cranial neuropathy and review the recent pertinent literature.
\end{abstract}

\section{Introduction}

Giant cell tumor (GCT) is a benign but locally aggressive bone tumor that usually involves the end of long bones. It is a relatively common neoplasm in patients, constituting 5 to $10 \%$ of all benign bone tumors. ${ }^{1,2}$ Most of these tumors occur in the long bones in the epiphyseal segment within the bone marrow of the bone. In the long bones, they tend to occur at the distal femur, proximal tibia, proximal humerus, and distal radius. $^{3}$

The pathologic hallmark of this lesion is a pattern of osteolytic destruction. There are, however, similar bony tumors that can mimic the clinical presentation of these lesions. The differential diagnosis of a GCT is therefore wide and consists of giant cell reparative granuloma, chondroblastoma, aneurysmal bone cyst, and enchondroma. Giant cell reparative granulomas are known to have a more benign course, with complete cure following surgical curettage alone.
GCTs, in contrast, have a high recurrence rate of 40 to $60 \%{ }^{4}$ with a $10 \%$ risk for malignant transformation. Despite benign histology, 1 to $4 \%$ metastasize to the lungs. ${ }^{5}$ Approximately $2 \%$ of GCTs occur in the craniofacial skeleton with a predilection for the ethmoid, sphenoid, and temporal bones. ${ }^{6}$ The skull base location is unique and not commonly described.

\section{Clinical Features: Signs and Symptoms of the Skull Base}

Hearing loss, headache, tinnitus, and subcutaneous masses are the most commonly reported symptoms in GCTs of the skull base. ${ }^{7,8}$ Findings on examination are minimal including micro-otoscopy because these tumors originate in the deeper structures of the temporal/sphenoid bone. Facial nerve and lower cranial nerve involvement has been observed in advanced stages of the disease; pain is an received

July 3, 2014

accepted after revision

October 22, 2014

published online

February 18, 2015
DOI http://dx.doi.org/

10.1055/s-0034-1396656. ISSN 2193-6366.
@ 2015 Georg Thieme Verlag KG
Stuttgart · New York

License terms

(1) $\circledast \circledast$ 
uncommon complaint. ${ }^{7}$ Hearing loss can be either conductive due to involvement of the middle ear or sensorineural due to involvement of the otic capsule. ${ }^{8}$ Radiographically, these tumors occupy the middle cranial fossa, the temporomandibular joint, and the infratemporal fossa. Computed tomography (CT) and magnetic resonance imaging (MRI) are used to evaluate the extent of bony erosion and the extent of soft tissue involvement. ${ }^{4}$ GCTs typically are hypointense on $\mathrm{T} 1$ and $\mathrm{T} 2$ and enhance with the administration of gadolinium. ${ }^{4}$ GCTs rarely exhibit calcifications; however, when calcifications are present, other pathology should be considered such as chordoma, craniopharyngioma, meningioma, and chondrosarcoma. ${ }^{9}$

In this case report study, we report the first description of a GCT within the internal auditory canal (IAC) causing cranial neuropathy.

\section{Case Report}

Patient is a 47-year-old woman who presented to the neurosurgery clinic with significant headache, dizziness, and right ear pain. She reported complaints of a dramatic decrease in hearing in her right ear and disabling tinnitus over the course of the past year. She had no past medical history.

\section{Physical Examination}

Results of her general physical and neurologic examination were unremarkable, except for mild sensorineural hearing loss in her right ear and a positive Romberg sign. Her facial nerve function was intact with no signs of facial asymmetry. Her audiometric evaluation disclosed a $4 \%$ discrimination score and a 35 to $50 \mathrm{Db}$ mild to moderate downsloping sensorineural hearing loss in her right ear with word recognition significantly lower than would be expected given her pure tone thresholds.

\section{Laboratory Values}

All preoperative basic chemistry and hematologic laboratory values were within normal limits. Calcium, magnesium, and phosphorus were also within normal limits.

An MRI was performed that revealed an enhancing lesion at the level of the right cerebellopontine angle cistern (CPA) with extension into the right IAC (-Fig. 1). Our institution typically performs CT scans on CPA lesions to evaluate the bony anatomy, for preoperative planning, and we prefer to fuse the CT and MRI scans in stereotactic operative guidance systems. The CT scan of the right IAC demonstrated a lytic lesion involving the right temporal bone and the posterior wall of the right IAC. The lesion measured $1.3 \times 1.2 \times 0.8 \mathrm{~cm}$. The lesion involved the medial aspect of the vestibular aqueduct but spared the vestibule, semicircular canals, and cochlea. The mass was inferior to the intracanalicular portions of cranial nerves VII and VIII complexes. The presumptive diagnosis based on imaging was meningioma, however; aneurysmal bone cyst, osteosarcoma, vestibular schwannoma, and brown tumor of hyperparathyroidism (lower suspicion based on normal serum calcium) were also considered in the differential diagnosis.

\section{Operation}

Based on the patient's clinical deterioration in hearing, persistent headaches, and vertigo, and the atypical appearance of bony destruction on CT scan, a discussion with the patient outlined the necessity for operative intervention. A decision was made to proceed with skull base tumor resection. The surgery would entail a right presigmoid/retrolabyrinthine approach combined with posterior (retro) sigmoid approach. The patient was placed supine with a shoulder roll and placed in a Mayfield head holder. Somatosensory evoked potentials and motor potentials were attached as well. The combined retro/presigmoid craniectomy was performed, and the IAC was exposed. The inferior and superior aspect of the

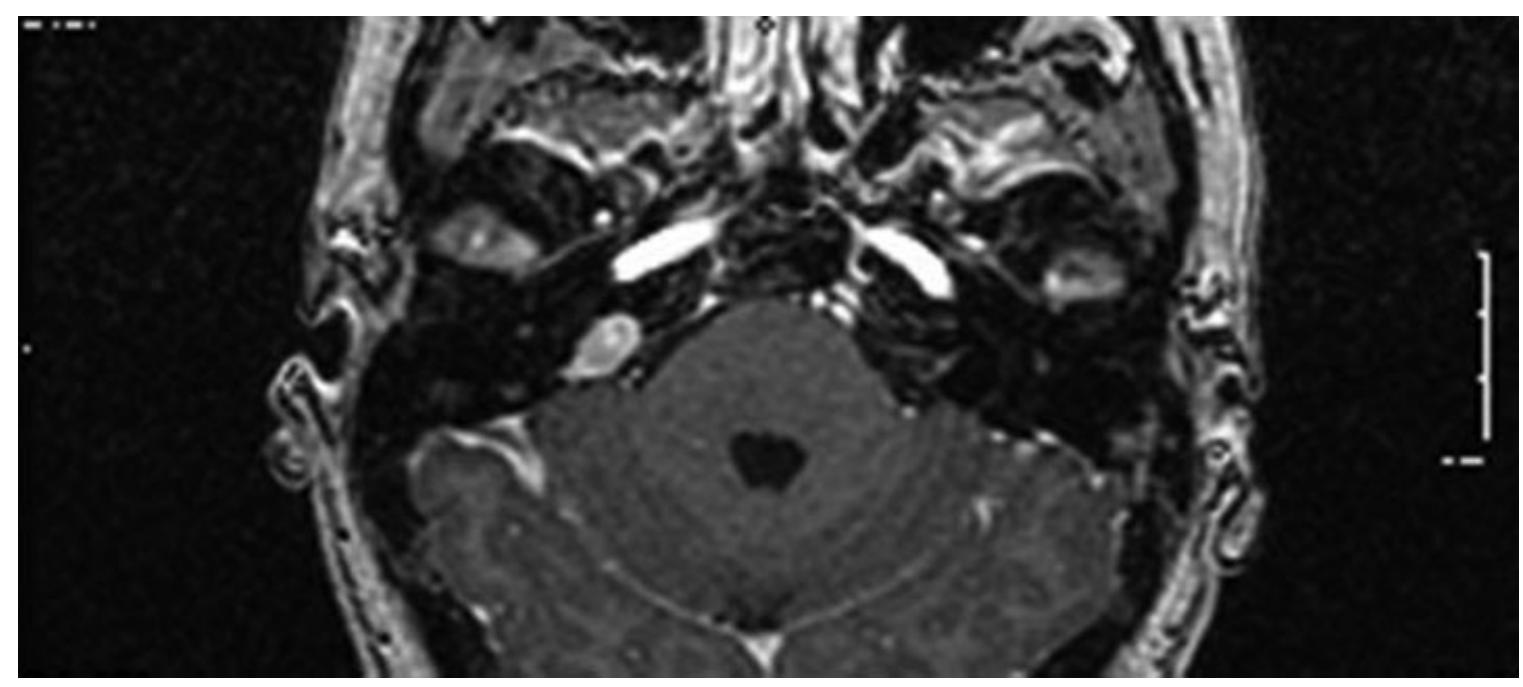

Fig. 1 Axial contrast-enhanced magnetic resonance imaging demonstrating a uniformly enhancing lesion involving the right cerebellopontine angle cistern with extension into the right internal auditory canal. The imaging lead to a presumptive diagnosis of a meningioma. However, a dural tail was not identified, raising the suspicion for an alternative pathology. 
tumor was removed and the IAC was skeletonized from within the temporal bone. Intraoperatively it appeared that a gross total resection (GTR) was achieved. Neurophysiologic monitoring demonstrated a drop in facial motor potentials at the end of the case. The tumor had a soft and granular consistency. A frozen section was sent intraoperatively, and the preliminary report stated the tissue was consistent with a meningioma (-Fig. 2).

\section{Surgical Pathology}

The surgical pathology report identified the specimen as consisting of multiple tan/brown soft tissue fragments aggregating up to $2.0 \times 1.2 \times 0.4 \mathrm{~cm}$. Microscopy revealed the lesion to be composed of a proliferation of monomorphic spindle and plump epithelioid cell proliferation admixed with numerous multinucleated giant cells (-Fig. 2). The mitotic rate was up to 4 per 10 high power fields. There was no significant atypia, coagulative tumor cell necrosis, or neoplastic osteoid, thus ruling out osteosarcoma. Also, microscopy did not demonstrate honeycombed blood-filled spaces that would have been consistent with an aneurysmal bone cyst. Immunohistochemistry showed immunoreactivity for CD 68 in both the multinucleated giant cells and a proportion of mononuclear cells (figure inset). The cells were negative for epithelial membrane antigen and progesterone receptor. Negative immunoreactivity for epithelial membrane antigen and progesterone receptor ruled out a meningioma. The morphological and immunophenotypic features were consistent with a giant cell rich fibrohistiocytic lesion. Furthermore, with normal parathyroid function and calcium levels, brown tumor of hyperparathyroidism was also ruled out.

\section{Postoperative Course}

The patient awoke from anesthesia with a right-side facial nerve palsy, consistent with a House-Brackmann grade IV. She was started on high-dose dexamethasone that was tapered over a week. Her hearing postoperatively was stable, and she is pending formal audiometric evaluation. Of note, the patient's vertigo did improve postoperatively with abatement of her Romberg sign and dizziness. On postoperative follow-up 6 weeks later, the patient had improved to a HouseBrackmann grade III with independent eye closure. There were no signs of postoperative cerebrospinal fluid leak, either clinically with clear fluid egress, or radiographically with air or fluid on imaging, 6 weeks postoperatively.

\section{Discussion}

GCTs commonly involve the sphenoid and temporal bones in the craniofacial skeleton. ${ }^{6}$ We report here this first description of a GCT primarily affecting the IAC and causing cranial neuropathy. This skull base location and proximity to the cranial nerves presents several challenges in their surgical management. Because GCT is primarily a locally aggressive tumor and rarely metastasizes, the most common treatment paradigm involves local curettage and a wide excision. This becomes more difficult, however, when the bony margins involve the skull base and cranial nerves. This complicates treatment of the GCT in the craniofacial skeleton as opposed

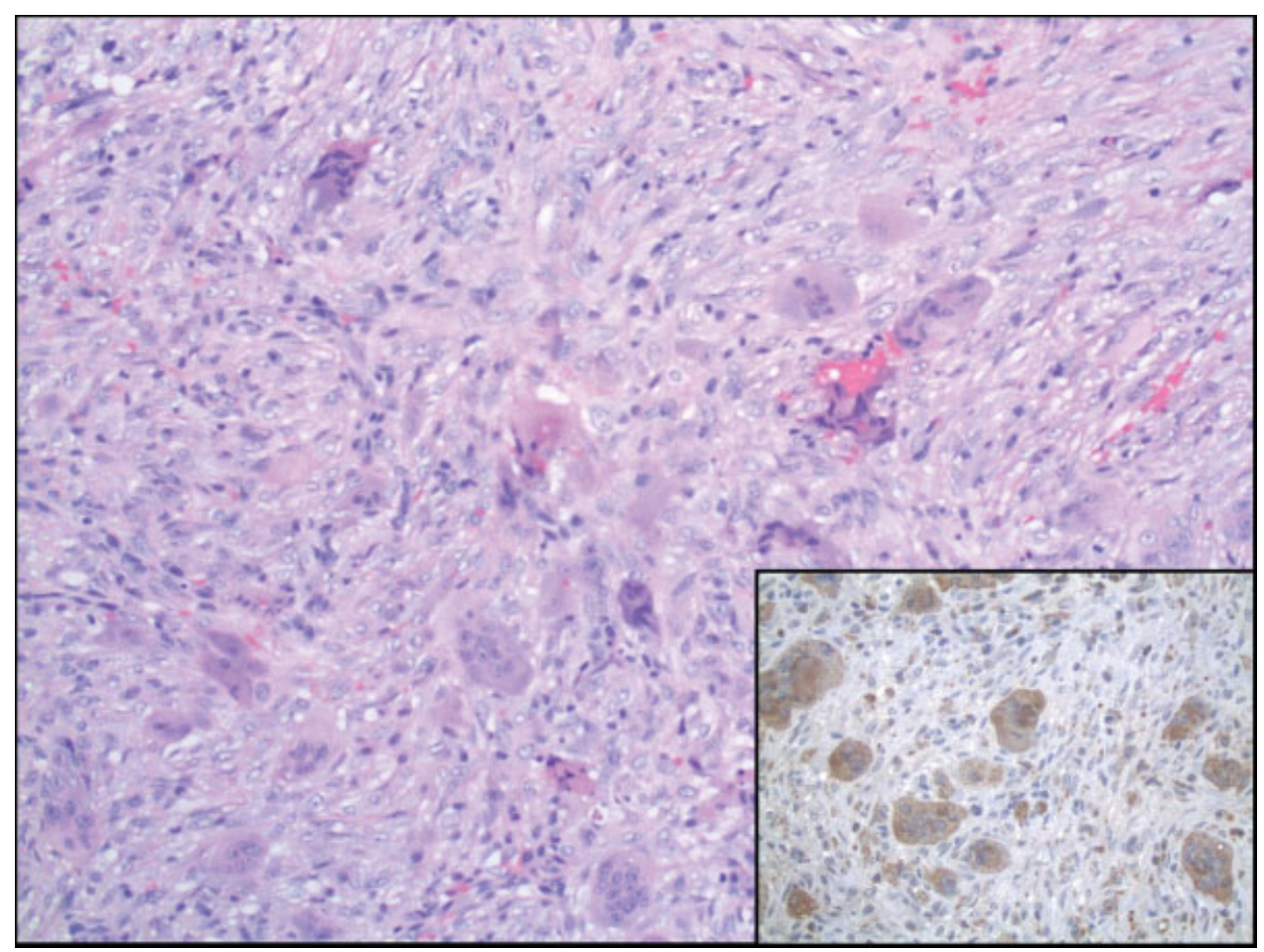

Fig. 2 Photomicrograph showing proliferation of monomorphic plump spindle cells, admixed with multinucleated giant cells (hematoxylin and eosin: magnification $\times 200$ ). Inset shows immunoreactivity for CD68 in the multinucleated cells as well as the spindle cells (avidin-biotinperoxidase magnification $\times 200$ ). Findings were consistent with giant cell tumor. 
to GCTs in long bones. Despite GTR, GCTs still recur locally in 10 to $50 \%$ of patients as reported in some clinical series. ${ }^{10}$

Due to the location of these tumors and their propensity to recur locally, complete excision without damage to regional critical structures, especially cranial nerves, is challenging. Tumor removal in a complete fashion is the goal of the treatment because recurrence in these areas will necessitate revision surgery that increases the chance of cranial nerve injury as well as local recurrence. However, when the tumor is large, internal debulking is necessary. ${ }^{11}$ Therefore it is imperative that the first surgical resection be directed at GTR with preservation of neurovascular structures. In the temporal bone this is particularly important given the sensitivity of the cochleovestibular nerve and the complex course of the facial nerve.

\section{Staging}

GCTs are often characterized by extent of invasion prior to operative planning. Stage I tumors are located within a small area in the bone; stage II tumors are expansile within the cortex. Stage III tumors are defined as having breached the cortex and extending into the adjacent soft tissues. ${ }^{12}$

\section{Histopathology and Cell Biology}

GCTs are characterized by uniform layers of ovoid mononuclear cells interspersed with multinucleated osteoclast-like giant cells, which is a pathognomonic histologic sign of this tumor. ${ }^{11-13}$ GCTs consist mainly of three cell types ${ }^{14}$ : spindle shaped cells, mononuclear cells, ${ }^{15}$ and multinucleated osteoclast-like giant cells. ${ }^{15,16}$ The osteoclast-like giant cells and their precursors express a receptor activator of nuclear factor KB (RANK). The mononuclear cells express the RANK ligand $(\mathrm{RANKL})^{17}$ that is essential to osteoclast function, formation, and survival. It is theorized that the recruitment of osteoclastlike giant cells is related to the expression of RANKL and that the giant cells mediate the osteolytic nature of the tumor. ${ }^{17-21}$ This finding has led to treatment paradigms targeting the RANKL.

Emphasis has been placed on the differentiation between the giant cell reparative granuloma and GCT due to the proposed differences in their nature and clinical course. ${ }^{22}$ These differences are based mostly on the clinical behavior of GCTs in long bones. However, there have been case reports of giant cell reparative granulomas in the skull base mimicking intracranial tumors. ${ }^{23}$ Hence it is necessary to understand the pathology and differences in the treatment of GCT and giant cell reparative granulomas. Giant cell reparative granulomas are known to have a more benign course, with complete cure following surgical curettage alone. GCTS, in contrast, have a high recurrence rate of 40 to $60 \%$ with a risk for malignant transformation and potential to metastasize ranging from $1 \%$ to $9 \%$, with the lung the most common location for metastases. $^{4}$

Although most literature is on GCTs of long bones, bisphosphonates and other antiosteoclastic drugs have shown efficacy in various trials for treating local and metastatic
GCTs. ${ }^{12}$ Tse et al administered two doses of intravenous bisphosphonate before surgery and at 3 to 4 weeks between each dose for three doses and 3 months of additional oral bisphosphonate therapy. In the treatment group, $4.2 \%$ developed local recurrence; in the control group, 30\% developed recurrence. $^{12}$ It is hypothesized that bisphosphonate use results in apoptosis of GCT cells that can be used as an adjunct to surgical resection. ${ }^{24}$

Intraoperatively, it is difficult to distinguish GCT from other pathology based on gross appearance and texture. If GCT is suspected based on radiographic features, the pathologist should be notified before frozen sectioning.

\section{Origin in the Skull Base}

The skull is an uncommon location for GCTs. The GCTs arise from nonosteogenic stromal cells of bone marrow at the epiphysis in cartilaginous bone. ${ }^{25}$ The temporal bone consists of squamous and petromastoid components. GCTs are found to develop from petromastoid temporal bone more so than the squamous temporal bone. ${ }^{26}$ The radiologic and clinical features in our case favor the origin from the petrous portion of the temporal bone. It is still the belief of some authors that GCTs and giant cell reparative granulomas (GCRGs) encompass a single disease process that is influenced by both the age of the patient and the site of occurrence. ${ }^{27}$

The first case of GCRG in the temporal bone was reported by Hirschl and Katz. ${ }^{28,29}$ Some specimens have distinct histologic features of either GCT or GCRG, but there may be similarities in the microscopic appearances of others. ${ }^{30}$ These overlapping lesions reconfirm the hypothesis that GCT and GCRG may be a single spectrum of pathology. Trauma has been implicated in the etiology of both GCTs and GCRGs, as in the present case, and suggests a correlation between the two lesions. $^{31}$ Few GCTs have been reclassified as GCRGs due to the confusion in these lesions in the head and neck region. It is still a possibility that lesions following trauma are not true neoplasms and those giant cell granulomas that lack the history of trauma are true neoplastic lesions.

GCTs are uncommon in the skull and comprise $<1 \%$ of all reported bone tumors. ${ }^{32,33}$ Moreover, GCTs commonly involve the sphenoid and temporal bones of the middle cranial fossa that are formed by the enchondral bone. ${ }^{26}$ From a histologic perspective, GCTs are a benign lesion; however, when located in the skull base or sphenoid bone, these locally aggressive tumors can be clinically devastating due to their aggressive local destruction and their proximity to vital neurologic structures. ${ }^{34-36}$ GCTs that present in the skull base are surgically challenging lesions, and the use of adjuvant therapy with external-beam radiotherapy has been reported without clear benefit and without obvious radiologic regression. ${ }^{37}$ More research is needed in radiation as a treatment for GCT. As reported in the literature, the lack of efficacy of radiation on GCT has led authors toward surgical management as their primary modality of treatment for GCT, despite the morbidity as noted in our case presentation.

As an alternative to radiotherapy, bisphosphonate treatment for GCTs has been proposed in the literature as well, 
with data showing lower local recurrence and promising outcomes. ${ }^{12,24}$ However, this modality needs further clinical evaluation.

\section{Treatment}

In a review of the head and neck/skull base literature, surgery is still the definitive treatment modality for GCTs. Approximately $80 \%$ of patients with primary GCTs (craniofacial and long bone) have surgically amenable lesions; however, the morbidity associated with surgery is substantial, especially with regard to GCTs of the skull base. The reported recurrence rate is 10 to $75 \%$ depending on the location and size of the lesion, as well as the extent of surgical resection. ${ }^{38,39}$ There is a paucity of literature on recurrence of skull patients with GCT lesions who are not amenable to surgical resection and have limited treatment options. Arterial embolization and radiation therapy are treatment possibilities, although radiation can lead to transformation of GCTs to high-grade sarcomas, or it can lead to development of secondary malignancies. ${ }^{40}$ Reports have shown that patients with pulmonary GCT metastases have favorable life expectancies; however, distant metastases of GCTs have not been shown to respond to chemotherapy and carry a poor prognosis. ${ }^{41}$

\section{Causative Factors}

Although the etiology of GCTs is uncertain, current theories for the origin of GCTs include neoplastic, toxic, allergic, genetic, inflammatory, and traumatic causes. ${ }^{42,43}$ True neoplastic lesions are thought to originate from the connective tissue of bone, whereas inflammatory lesions are thought to arise from the periosteum. Differentiating periosteal lesions from marrow or soft tissue lesions, either clinically or radiographically, is challenging due to the size of the tumor at diagnosis. ${ }^{44}$ Thus there is debate on the etiology of GCTs and whether they are inflammatory reactions as opposed to a true neoplastic lesion..$^{45}$ Haque and Moatasim describes GCTs as a nonneoplastic condition that is a reactive process resulting from weak local vasculature in the bone. ${ }^{45}$

\section{Radiology}

Radiologic features of GCT can help establish a diagnosis. GCTs typically demonstrate a meta-epiphyseal location with an extension into subchondral bone. ${ }^{4}$ On temporal bone $\mathrm{CT}$, GCTs are identified as osteolytic lesions with a soft tissue component resulting in bony erosion and distinct margins. ${ }^{46}$ GCTs have been described as having a "soap bubble appearance" on CT scan as well. ${ }^{47}$ Although CT scan is essential for the delineation of bony anatomy and erosion, MRI is the diagnostic modality of choice for GCTs. Both cystic and solid components of the lesion can be observed on MRI. Lesions are typically isointense on $\mathrm{T} 1$ and low to intermediate intensity on $\mathrm{T} 2$, with heterogeneous enhancement after administration of intravenous gadolinium. ${ }^{4,48}$

The CT scan in our patient revealed smooth expansion of bone with areas of bone destruction and a characteristic soap bubble matrix. ${ }^{47}$ Also the lesion was isointense to the surrounding brain parenchyma on both T1- and T2-weighted images with intense postcontrast enhancement.

GCTs have shown increased uptake of technetium-99m; however, it is both a nonspecific and unreliable marker in defining extent of tumor, and its use is limited to metastatic or multicentric GCTs. ${ }^{49}$ Positron emission tomography (PET) scans have demonstrated utility in the diagnosis of malignant and recurring GCTs, in addition to surveillance imaging for monitoring response to therapy. ${ }^{49}$

\section{Emerging Treatments}

As described earlier, the expression of the RANKL has been implicated in giant cell recruitment and the osteolytic nature of GCTs. New therapy has been directed at inhibiting the RANKL.

Denosumab is a fully human monoclonal antibody that specifically inhibits RANKL, thus inhibiting osteoclastmediated bone destruction. ${ }^{13}$ Denosumab has demonstrated suppression of bone turnover in patients with multiple myeloma, breast and prostate cancer, bone metastases, and osteolytic bone disease. ${ }^{50-53}$ Current studies are investigating the efficacy of denosumab in patients with GCT. With its mechanism of inhibition of RANKL, it may inhibit bone destruction and eliminate giant cells. ${ }^{13}$ PET/CT may be the ideal imaging study to ascertain serial progression to treatment.

\section{Surgical Management}

Surgical resection remains the mainstay and primary treatment modality of GCTs of the head, neck, and long bones. GCTs of the skull base present a challenge due to the complex anatomy and intimate nature of the neurovascular elements. GTR with preservation of the facial nerve and lower cranial nerves is the goal of surgery, although with GCTs of the temporal bone, GTR may not possible. In our case, GTR was attempted; however, there was compromise of the facial nerve. The surgical approach to the tumor must be evaluated on a case-by-case basis. For tumors involving the temporal bone, some authors have advocated an infratemporal fossa approach, and for tumors involving the middle cranial fossa, a combined middle fossa and infratemporal approach has been suggested. ${ }^{7}$ The surgical treatment of choice is intralesional curettage, burring with a high-speed drill, and packing with bone cement (polymethyl methacrylate). Furthermore, some authors suggest chemical adjuncts, if applicable, such a hydrogen peroxide or phenol. ${ }^{38}$ Balke et al reports a reduction of recurrence rate by a factor of 28 with the addition of a chemical adjunct. $^{54}$

\section{Radiation}

Postoperative radiation for subtotal resection remains controversial. $^{55}$ In a case series by Roeder et al, the authors concluded intensity-modulated radiotherapy (IMRT) is a feasible option for subtotal resection of GCTs, noting 4 of 5 patients with symptom relief and local control. ${ }^{56}$ 
Furthermore, in a review of GCT of the sphenoid and temporal bones, Glasscock and Hunt noted recurrence rates of 60 to $70 \%$ when radiotherapy was used as a single modality. ${ }^{57}$ Typically, radiation should be reserved for those patients who are not surgical candidates, have GCTs not amenable to surgery due to location and procedural risk, or have multiple recurrences after surgical resection. More research is needed to delineate the role of radiation in the management of GCTs.

\section{Conclusion}

In this case report study we report the first description of a GCT within the IAC causing cranial neuropathy. GCTs are locally aggressive benign lesions that occur in long bones, with $2 \%$ occurring in the craniofacial skeleton, most commonly within the sphenoid and temporal bones. Patients may present with facial nerve symptoms and hearing loss late in the presentation of the disease. GTR remains the mainstay of treatment; however, in lesions of the temporal bone this may not be feasible. Postoperative cranial neuropathy and/or weakness may occur from the extensive bony involvement. This may happen even in a delayed fashion. Local recurrence correlates with the size of the lesion and the extent of resection and curettage. Although controversial, IMRT may be a possible treatment modality for subtotal resection and should be investigated further. Emerging technologies for treatment are being developed and may provide improved patient outcomes.

\section{References}

1 Boons HW, Keijser LC, Schreuder HW, Pruszczynski M, Lemmens JA, Veth RP. Oncologic and functional results after treatment of giant cell tumors of bone. Arch Orthop Trauma Surg 2002;122(1): 17-23

2 Dahlin DC, Unni KK. Bone Tumors: General Aspects and Data on 8,542 Cases. 4th ed. Springfield, IL: Charles C Thomas; 1986

3 Wang HC, Chien SH, Lin GT. Management of grade III giant cell tumors of bones. J Surg Oncol 2005;92(1):46-51

4 Murphey MD, Nomikos GC, Flemming DJ, Gannon FH, Temple HT, Kransdorf MJ. From the archives of AFIP. Imaging of giant cell tumor and giant cell reparative granuloma of bone: radiologicpathologic correlation. Radiographics 2001;21(5):1283-1309

5 Szendröi M. Giant-cell tumour of bone. J Bone Joint Surg Br 2004; 86(1):5-12

6 Marioni G, Marchese-Ragona R, Guarda-Nardini L, et al. Giant cell tumour (central giant cell lesion) of the maxilla. Acta Otolaryngol 2006;126(7):779-781

7 Prasad SC, Piccirillo E, Nuseir A, et al. Giant cell tumors of the skull base: case series and current concepts. Audiol Neurootol 2014; 19(1):12-21

8 Isaacson B, Berryhill W, Arts HA. Giant-cell tumors of the temporal bone: management strategies. Skull Base 2009;19(4):291-301

9 Rock JP, Mahmood A, Cramer HB. Giant cell tumor of the skull base. Am J Otol 1994;15(2):268-272

10 Sung HW, Kuo DP, Shu WP, Chai YB, Liu CC, Li SM. Giant-cell tumor of bone: analysis of two hundred and eight cases in Chinese patients. J Bone Joint Surg Am 1982;64(5):755-761

11 Blacklock JB, Weber RS, Lee YY, Goepfert H. Transcranial resection of tumors of the paranasal sinuses and nasal cavity. J Neurosurg 1989;71(1):10-15
12 Tse LF, Wong KC, Kumta SM, Huang L, Chow TC, Griffith JF. Bisphosphonates reduce local recurrence in extremity giant cell tumor of bone: a case-control study. Bone 2008;42(1):68-73

13 Thomas D, Henshaw R, Skubitz K, et al. Denosumab in patients with giant-cell tumour of bone: an open-label, phase 2 study. Lancet Oncol 2010;11(3):275-280

14 Goldring SR, Schiller AL, Mankin HJ, Dayer JM, Krane SM. Characterization of cells from human giant cell tumors of bone. Clin Orthop Relat Res 1986;(204):59-75

15 Liao TS, Yurgelun MB, Chang SS, et al. Recruitment of osteoclast precursors by stromal cell derived factor-1 (SDF-1) in giant cell tumor of bone. J Orthop Res 2005;23(1):203-209

16 Hanaoka H, Friedman B, Mack RP. Ultrastructure and histogenesis of giant-cell tumor of bone. Cancer 1970;25(6):1408-1423

17 Roux S, Mariette X. RANK and RANKL expression in giant-cell tumour of bone. Lancet Oncol 2010;11(6):514

18 Fuller K, Wong B, Fox S, Choi Y, Chambers TJ. TRANCE is necessary and sufficient for osteoblast-mediated activation of bone resorption in osteoclasts. J Exp Med 1998;188(5):997-1001

19 Huang L, Xu J, Wood DJ, Zheng MH. Gene expression of osteoprotegerin ligand, osteoprotegerin, and receptor activator of NFkappaB in giant cell tumor of bone: possible involvement in tumor cell-induced osteoclast-like cell formation. Am J Pathol 2000; 156(3):761-767

20 Lacey DL, Tan HL, Lu J, et al. Osteoprotegerin ligand modulates murine osteoclast survival in vitro and in vivo. Am J Pathol 2000; 157(2):435-448

21 Lacey DL, Timms E, Tan HL, et al. Osteoprotegerin ligand is a cytokine that regulates osteoclast differentiation and activation. Cell 1998;93(2):165-176

22 Schlorf RA, Koop SH. Maxillary giant cell reparative granuloma. Laryngoscope 1977;87(1):10-17

23 Ciappetta P, Salvati M, Bernardi C, Raco A, Di Lorenzo N. Giant cell reparative granuloma of the skull base mimicking an intracranial tumor. Case report and review of the literature. Surg Neurol 1990; 33(1):52-56

24 Chang SS, Suratwala SJ, Jung KM, et al. Bisphosphonates may reduce recurrence in giant cell tumor by inducing apoptosis. Clin Orthop Relat Res 2004;(426):103-109

25 Leonard J, Gökden M, Kyriakos M, Derdeyn CP, Rich KM. Malignant giant-cell tumor of the parietal bone: case report and review of the literature. Neurosurgery 2001;48(2):424-429

26 Pai SB, Lalitha RM, Prasad K, Rao SG, Harish K. Giant cell tumor of the temporal bone-a case report. BMC Ear Nose Throat Disord 2005;5:8

27 Auclair PL, Cuenin P, Kratochvil FJ, Slater LJ, Ellis GL. A clinical and histomorphologic comparison of the central giant cell granuloma and the giant cell tumor. Oral Surg Oral Med Oral Pathol 1988; 66(2):197-208

28 Katz A, Hirschl S. Giant cell reparative granuloma in the temporal bone. Arch Otolaryngol 1974;100(5):380-382

29 Hirschl S, Katz A. Giant cell reparative granuloma outside the jaw bone. Diagnostic criteria and review of the literature with the first case described in the temporal bone. Hum Pathol 1974;5(2):171-181

30 Saw S, Thomas N, Gleeson MJ, Bódi I, Connor S, Hortobágyi T. Giant cell tumour and central giant cell reparative granuloma of the skull: do these represent ends of a spectrum? A case report and literature review. Pathol Oncol Res 2009;15(2):291-295

31 Williams JC, Thorell WE, Treves JS, Fidler ME, Moore GF, Leibrock LG. Giant cell reparative granuloma of the petrous temporal bone: a case report and literature review. Skull Base Surg 2000;10(2): 89-93

32 Dahlin DC. Caldwell Lecture. Giant cell tumor of bone: highlights of 407 cases. AJR Am J Roentgenol 1985;144(5):955-960

33 Goldenberg RR, Campbell CJ, Bonfiglio M. Giant-cell tumor of bone. An analysis of two hundred and eighteen cases. J Bone Joint Surg Am 1970;52(4):619-664 
34 Emley WE. Giant cell tumor of the sphenoid bone. A case report and review of the literature. Arch Otolaryngol 1971;94(4): 369-374

35 Bertoni F, Unni KK, Beabout JW, Ebersold MJ. Giant cell tumor of the skull. Cancer 1992;70(5):1124-1132

36 Wolfe JT III, Scheithauer BW, Dahlin DC. Giant-cell tumor of the sphenoid bone. Review of 10 cases. J Neurosurg 1983;59(2): 322-327

37 Zorlu F, Selek U, Soylemezoglu F, Oge K. Malignant giant cell tumor of the skull base originating from clivus and sphenoid bone. J Neurooncol 2006;76(2):149-152

38 Balke M, Ahrens H, Streitbuerger A, et al. Treatment options for recurrent giant cell tumors of bone. J Cancer Res Clin Oncol 2009; 135(1):149-158

39 Malawer M, Helman LJ, O'Sullivan B. Giant cell tumor of the bone. In: DeVita VT Jr, Lawrence TS, Rosenberg SA, eds. Cancer: Principles and Practice of Oncology. 8th ed. Philadelphia, PA: Lippincott Williams \&Wilkins; 2008

40 Brien EW, Mirra JM, Kessler S, Suen M, Ho JK, Yang WT. Benign giant cell tumor of bone with osteosarcomatous transformation ("dedifferentiated" primary malignant GCT): report of two cases. Skeletal Radiol 1997;26(4):246-255

41 Siebenrock KA, Unni KK, Rock MG. Giant-cell tumour of bone metastasising to the lungs. A long-term follow-up. J Bone Joint Surg $\mathrm{Br} 1998 ; 80(1): 43-47$

42 Grover R, Grobbelaar AO, Richman PI, Smith PJ. Measurement of invasive potential provides an accurate prognostic marker for giant cell tumour of tendon sheath. J Hand Surg [Br] 1998;23(6): 728-731

43 Abdullah A, Abdullah S, Haflah NH, Ibrahim S. Giant cell tumor of the tendon sheath in the knee of an 11-year-old girl. J Chin Med Assoc 2010;73(1):47-51

44 Baba AI, Câtoi C. Comparative Oncology. Bucharest, Romania: The Publishing House of the Romanian Academy; 2007

45 Haque AU, Moatasim A. Giant cell tumor of bone: a neoplasm or a reactive condition? Int J Clin Exp Pathol 2008;1(6):489-501
46 Iizuka T, Furukawa M, Ishii H, et al. Giant cell tumor of the temporal bone with direct invasion into the middle ear and skull base: a case report. Case Rep Otolaryngol 2012;2012:690148

47 Razek AA. Imaging appearance of bone tumors of the maxillofacial region. World J Radiol 2011;3(5):125-134

48 Herman SD, Mesgarzadeh M, Bonakdarpour A, Dalinka MK. The role of magnetic resonance imaging in giant cell tumor of bone. Skeletal Radiol 1987;16(8):635-643

49 Purohit S, Pardiwala DN. Imaging of giant cell tumor of bone. Indian J Orthop 2007;41(2):91-96

50 Body JJ, Facon T, Coleman RE, et al. A study of the biological receptor activator of nuclear factor-kappaB ligand inhibitor, denosumab, in patients with multiple myeloma or bone metastases from breast cancer. Clin Cancer Res 2006;12(4):1221-1228

51 Fizazi K, Lipton A, Mariette X, et al. Randomized phase II trial of denosumab in patients with bone metastases from prostate cancer, breast cancer, or other neoplasms after intravenous bisphosphonates. J Clin Oncol 2009;27(10):1564-1571

52 Lipton A, Steger GG, Figueroa J, et al. Randomized active-controlled phase II study of denosumab efficacy and safety in patients with breast cancer-related bone metastases. J Clin Oncol 2007;25(28): 4431-4437

53 Lipton A, Steger GG, Figueroa J, et al. Extended efficacy and safety of denosumab in breast cancer patients with bone metastases not receiving prior bisphosphonate therapy. Clin Cancer Res 2008; 14(20):6690-6696

54 Balke M, Schremper L, Gebert C, et al. Giant cell tumor of bone: treatment and outcome of 214 cases. J Cancer Res Clin Oncol 2008; 134(9):969-978

55 Watkins LD, Uttley D, Archer DJ, Wilkins P, Plowman N. Giant cell tumors of the sphenoid bone. Neurosurgery 1992;30(4):576-581

56 Roeder F, Timke C, Zwicker F, et al. Intensity modulated radiotherapy (IMRT) in benign giant cell tumors-a single institution case series and a short review of the literature. Radiat Oncol 2010;5:18-56

57 Glasscock ME III, Hunt WE. Giant-cell tumor of the sphenoid and temporal bones. Laryngoscope 1974;84(7):1181-1187 